\title{
Discussion at Chicago, October 23, 1895.
}

Mr. A. V. Аввотт:--The paper that we have just listened to appears to me one of the most valuable contributions to the literature of "fuse wire," as it contains the first (so far as I am aware) attempt to make an accurate, comprehensive and systematic study of the behavior of fuse wires, with apparatus and investigators who were fully competent to the task undertaken, and I for one am exceedingly indebted to Professor Stine for the information thus placed before us. There is one point, however, upon which I am not quite clear. In the circuit described by Professor Stine, and in the records of experiments, I do not discover whether any allowance has been made for the time constants of the relays used for determining the minute intervals of time under consideration. It has been shown that intervals of time as small as $\frac{1}{1200}$ of a second are involved, and it appears to me quite probable that the time constant of the induction coil used would be of sufficient magnitude to introduce considerable error when applied to the measurement of time intervals as short as .001 of a second.

It is possible that no better means could be devised, or those which would be more accurate, but in consideration of results so carefully worked up, it appears that the time constant of the relay or induction coil might introduce a serious error in the results, and my question is therefore only as to whether any allowance was made for the possible introduction of errors of this description.

Prof. Strne:-We have considered this point very carefully, but if you will note the connections, it is evident that the currents actuating the relays have at all times such small values that this error is negligible.

Mr. Aввотт:-Does not the relay require a sensible time to impress its record upon the paper after the actual depression of the key exciting the relay or the closing of the relay circuit, and is not this time a sensible fraction of the time which the relay is supposed to measure and record?

Prof. Stine:-There is undoubtedly a time lag in the action of the relays. Those were adjusted to as short range of armature movement as possible. The actual value of the time lag was of no consequence, providing the relays were adjusted to equal time lag. This adjustment was made as accurately as possible, thus rendering the relative time intervals extremely accurate. The time intervals were those showing the actual time of the throw of the switch and the blowing of the fuse.

Mr. Aввотт :-A still more important point is the bearing of the length of the fuse upon the disrupting current. I am not quite clear as to whether the experiments described indicate that after a certain length of fuse is reached, little or no variation in carrying capacity is observed. The disruption in the fuse is. 
caused by raising the temperature of the metal composing it, to such a point as will melt it. The necessary heat is obtained from the energy developed in the fuse by the current. In any given time, the amount of heat contributed to the fuse is proportional to the square of the current and the resistance of the fuse wire. There are three causes of dissipation of heat:

First: Radiation which is due to the amount of radiating surface presented by the fuse wire.

Second: The heat lost by conduction to the terminals of the fuse, and there dissipated.

Third: The amount of heat absorbed in raising the temperature of the fuse wire and in melting it.

I have always had the idea that if the length of fuse was so great that the amount of heat lost by conduction to terminals was an insensible fraction of the heat delivered to the fuse by the current, no further increase of length would vary the carrying capacity of the fuse. In examining the curves illustrating the paper, it appeared that these curves indicated an approach to this condition, but from the fact that the lines did not become parallel to the axis, indicated that this principle was not carried out to such an extent as I had previously imagined to be the case.

Now, one other point: Are there any curves which went into that point particularly? That is to say, the ratio of the length of the fuse to its carrying capacity and the time?

Prof. Stine:- Such a curve was platted, and an approximate equation derived therefrom. Further investigations seemed desirable, and for this reason it has been withheld. We hope to give our results in an early communication.

Mr. Аввотт:--I have always felt that the emphasis of experimental evidence should be directed to convincing the people of the advisability of using long fuse blocks, thereby contributing to the reliability of such protecting devices. I would also like to ask why it was that no experiments were carried on for higher currents than those which are shown. A greater proportion of the work seems to have dealt with currents of 40 amperes or under, while there are only one or two instances of the employment of 60 or 80 amperes. It would be interesting to know something of the value of the length of the fuse in its relation to currents of considerable magnitude, such as would be found upon our larger street railway circuits, and also the effect of alternating currents.

Mr. Ludwig Gutmann:-I would like to know from Prof. Stine whether other experiments were made showing the proper rating under heat conduction. Would it not be better to make fuses of such lengths that they could be rated with conduction present, and thus raise their sensitiveness? If the same fuse may be rated higher when covered, would not this be better?

Prof. Stine :-I think that this point is clearly emphasized in l aper. We have advised just the opposite procedure. It is 
difficult to rate the value of condition, owing to variations of contact and the character of the contact surface. It seems better to use a fuse under such conditions that its blowing point shall be normally that of the fuse itself.

Mr. Aввотт:--Prof. Stine shows that in all cases there is an apparent interval of one or two seconds in all fuses, no matter what the current is before the fuse ruptures.

It appears from these experiments that no matter what the size of the fuse, or how large the current, there is an appreciable interval of time in which the smallest fuse might carry almost an infinite current.

Prof. Stine:-I think the maximum current employed was 110 amperes. The time lag was $\frac{348}{1000}$ of a second for everything above 40 amperes, and for three ampere fuses the time lag was $\frac{148}{1000}$ of a second.

Mr. Аввотт:-From the care exercised in the experiments and the reliability of the apparatus used, it appears that we can certainly trust the time readings to .001 of a second, or thereabouts.

The experiments show that there is a sensible interval of time amounting to from one to three seconds, during which the fuse does not fail, no matter how large the current is to which it is exposed. It would be interesting to know to what extent this increase of current for the first few intervals of time could be carried. It seems quite certain that if a small fuse were exposed to a large current of some thousands of amperes, an enormous amount of heat would be given to the fuse, and it is a pertinent question as to what becomes of this heat, and why it is that the fuse does not fail more promptly.

Mr. Louts Privat :- When an are occurred on blowing the fuse, did you note whether the arc was sustained?

Prof. STINe:--We photographed an arc in a number of cases. Would that answer your question?

Mr. Privat :-Yes, partially. What I wished to get at was the destructive character of the arc. What is sufficient to cause a fire risk?

Prof. Stine:-That is a question we did not investigate, since we found the rupture of fuse to be quite uniform. One can scarcely speak of a sustained are in the rupture of the fuse wire itself. The arc occurs only when the rminals of the fuseblock are too near together. 